\title{
ZnO PROCESSING FOR INTEGRATED OPTIC SENSORS
}

\author{
WINFRIED H. G. HORSTHUIS
}

Department of Electrical Engineering, Twente University of Technology, P.O. Box 217, 7500 AE Enschede (The Netherlands)

(Received April 10,1985; revised July 12, 1985; accepted August 7, 1985)

$\mathrm{ZnO}$ thin films were sputter deposited onto oxidized silicon wafers. The film quality increased with increasing applied r.f. power. Characterization of the films was performed by measurements of the attenuation of the transverse electric $\mathrm{TE}_{0}$ optical guided mode. For an applied r.f. power of $2000 \mathrm{~W}$, the deposition rate was $220 \mathrm{~nm} \mathrm{~min}{ }^{-1}$, resulting in a mode attenuation of only $1.6 \mathrm{~dB} \mathrm{~cm}^{-1}$ for a film $0.8 \mu \mathrm{m}$ thick.

The refractive indices of the films were $99.5 \%$ (ordinary index) and $99.8 \%$ (extraordinary index) of the single-crystal values.

The step coverage on etched $\mathrm{SiO}_{2}$ profiles appeared to be very smooth, which simplifies the creation of waveguiding channels. The optical behaviour of multilayered waveguides consisting of $\mathrm{ZnO}$ and $\mathrm{SiO}_{2}$ films was studied. A prototype of a mode coupler in such a multilayer showed the feasibility of efficient electro-optic modulation in $\mathrm{ZnO}$-based waveguides.

\section{INTRODUCTION}

$\mathrm{ZnO}$ is often called a promising material for planar optical waveguides ${ }^{1-3}$. It is potentially low cost, can be sputter deposited onto many types of substrate and has large electromechanical, electro-optical and elasto-optical constants. However, in the last 2 years little attention has been paid to it. This could be explained by the difficulties which are met in the fabrication of single-mode waveguides with $\mathrm{ZnO}$. $\mathrm{ZnO}$ is normally deposited onto amorphous substrates such as fused quartz, glass or oxidized silicon. The high refractive index contrast between such substrates and the $\mathrm{ZnO}$ film implies very small channel dimensions (less than $0.5 \mu \mathrm{m}$ ) for single-mode operation. For integrated optic sensors several sensitive processes are reported ${ }^{4-6}$, depending on single-mode interferometers or coupled channel waveguides. Since single-mode channels can hardly be realized in $\mathrm{ZnO}$, we focused our attention on the application of multilayered single-mode slab waveguides. Two waveguides separated by an intermediate layer can be used to exploit coupling phenomena, with no demands being made on precise planar geometrical structures. Only film thicknesses and refractive indices determine the coupling process, which are both easy to control. 
In this paper the results of high rate sputtering of $\mathrm{ZnO}$ films are reported and compared with results of other groups in this field. Characterization of the films was performed by optical waveguiding measurements and occasionally scanning electron microscopy (SEM). It follows from several papers ${ }^{1-3}$ that these optical measurements give a good insight into the crystalline quality of the sputtered films. Conclusions can be drawn about the quality of the films from the absolute values of the refractive indices and the birefringence. Parriaux and Cochet $^{7}$ have shown that the $c$ axis orientation can be calculated from the measured refractive indices of anisotropic films such as $\mathrm{ZnO}$. The excellent step coverage of our sputtered films makes even the fabrication of low loss ridge waveguides possible.

We performed several experiments on multilayered waveguides. Results concerning attenuation and mode behaviour will be discussed in the subsequent sections.

\section{SPUTTER DEPOSITION OF $\mathrm{ZnO}$}

\subsection{Equipment}

We deposited our $\mathrm{ZnO}$ films using an r.f. reactive planar magnetron sputter unit, an apparatus which is rather similar to those of some other groups ${ }^{8,9}$. The system is evacuated with a turbomolecular pump, backed by a sorption vessel and a rotary pump. An additional liquid nitrogen coil is mounted on the inside of the belljar enabling the chamber to be evacuated to $7 \times 10^{-6} \mathrm{~Pa}$. We use a $99.999 \%$ pure zinc target of diameter 6 in and $99.999 \%$ pure oxygen as the sputter gas. The gas pressure during sputtering is electronically controlled using a precision leak valve. The substrates are steam oxidized silicon wafers with a (111) orientation. The substrate holder is placed above the target and can be heated to $500^{\circ} \mathrm{C}$ by means of an ohmic coil. If the substrate is heated to its maximum temperature, a minimum pressure of $1 \times 10^{-5} \mathrm{~Pa}$ can still be obtained. The r.f. source is capable of supplying $3 \mathrm{~kW}$ and is coupled to the target by means of a manually operated matching network.

\subsection{Results}

As usual, three main parameters are varied to obtain optimum sputter conditions, namely oxygen pressure, temperature and applied r.f. power. The pressure was varied between 2 and $0.5 \mathrm{~Pa}$, the lower value being limited by discharge instabilities. The temperature was varied from room temperature to $500^{\circ} \mathrm{C}$. Using the same r.f. power, two best values of $0.5 \mathrm{~Pa}$ and $470^{\circ} \mathrm{C}$ were obtained for pressure and temperature respectively. The key parameter in the determination of these values was the attenuation of the $\mathrm{TE}_{0}$ mode. Films sputtered with higher oxygen pressures or lower temperatures showed very high attenuation values, varying between 12 and $60 \mathrm{~dB} \mathrm{~cm}^{-1}$. The films sputtered at low temperature looked bluish because of a rather rough surface. Figure 1 shows the influence of the applied r.f. power on the attenuation of the $\mathrm{TE}_{0}$ mode. Attenuation decreases with increasing power, i.e. increasing rate. At about $2000 \mathrm{~W}$ the film quality stabilizes. Table I shows some data reported in several papers on $\mathrm{ZnO}$ for optical waveguides compared with our results. The loss figures concern the $\mathrm{TE}_{0}$ modes.

The more recent results of Maniv et al. ${ }^{11}$ are omitted from this table since they 


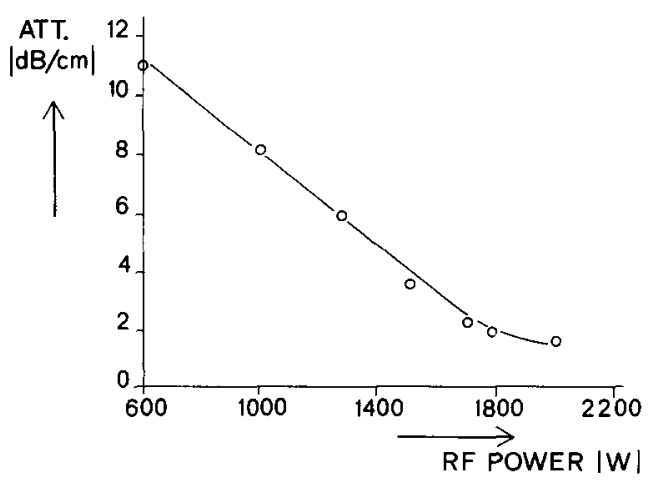

Fig. 1. Attenuation of the $\mathrm{TE}_{0}$ mode $v$ s. the applied sputter r.f. power.

did not attempt to obtain high quality optical films but merely studied the sputter process itself. Table I shows that our process has the advantage of the highest rate while retaining the quality of the films. It is very interesting to note that the results of Defranould ${ }^{10}$ are almost the same with respect to all aspects of sputtering although he used a d.c. magnetron. Unfortunately he does not report the optical quality of his films.

Since we used a large target (diameter, 6 in) we were able to sputter onto relatively large areas. The films on the 2 in wafers have a thickness uniformity which is better than $\pm 2 \%$, which also compares with that obtained by Defranould ${ }^{10}$.

The optical constants of the films sputtered at $1800 \mathrm{~W}$ or more are very close to the single-crystal values. We measured an ordinary index of $1.985 \pm 0.004$ and an extraordinary index of $2.007 \pm 0.004$. These values are respectively $99.5 \%$ and $99.8 \%$ of the single-crystal values (He-Ne light of wavelength $632.8 \mathrm{~nm}$ was used). The birefringence of our films is $0.85 \%$, which is almost the same as the single-crystal value of $0.80 \%$. These results indicate a high optical quality of the sputtered films.

For our purposes of integrated optic sensor applications we only need films up to $0.5 \mu \mathrm{m}$ thick. These thin films can be grown with a very good reproducibility; however, we experienced problems with thicker films. Optical attenuation of the $\mathrm{TE}_{0}$ mode increases sharply for films thicker than $1.3 \mu \mathrm{m}$. The appearance of these films becomes milky, indicating a rough surface. SEM pictures suggest a change in the film structure as the film becomes thicker. These observations could also have been made in the SEM pictures of other researchers. The negative comment of Maniv and Zangvilli ${ }^{12}$ on the reliability of SEM observations should be noted here. Ambersley and Pitt $^{8}$ also experienced a change in the columnar structure of their films with increasing thickness (above $4 \mu \mathrm{m}$ ). One of the reasons for this change could be that many small columns begin to combine, resulting in different growth rates. Yamamoto et al. ${ }^{3}$ used glass substrates with nearly the same thermal expansion coefficient as that of $\mathrm{ZnO}\left(4.5 \times 10^{-6}{ }^{\circ} \mathrm{C}^{-1}\right.$ and $4 \times 10^{-6}{ }^{\circ} \mathrm{C}^{-1}$ respectively) and produced very thick films without surface degradation. Since we used silicon substrates with a thermal expansion coefficient of $2.33 \times 10^{-6}{ }^{\circ} \mathrm{C}^{-1}$ and a high sputter temperature, severe stresses built up in thick $\mathrm{ZnO}$ films. These stresses could be the cause of the change in crystalline structure. We shall shortly be using Corning 7059 substrates as well in order to check the influence of these stresses. 

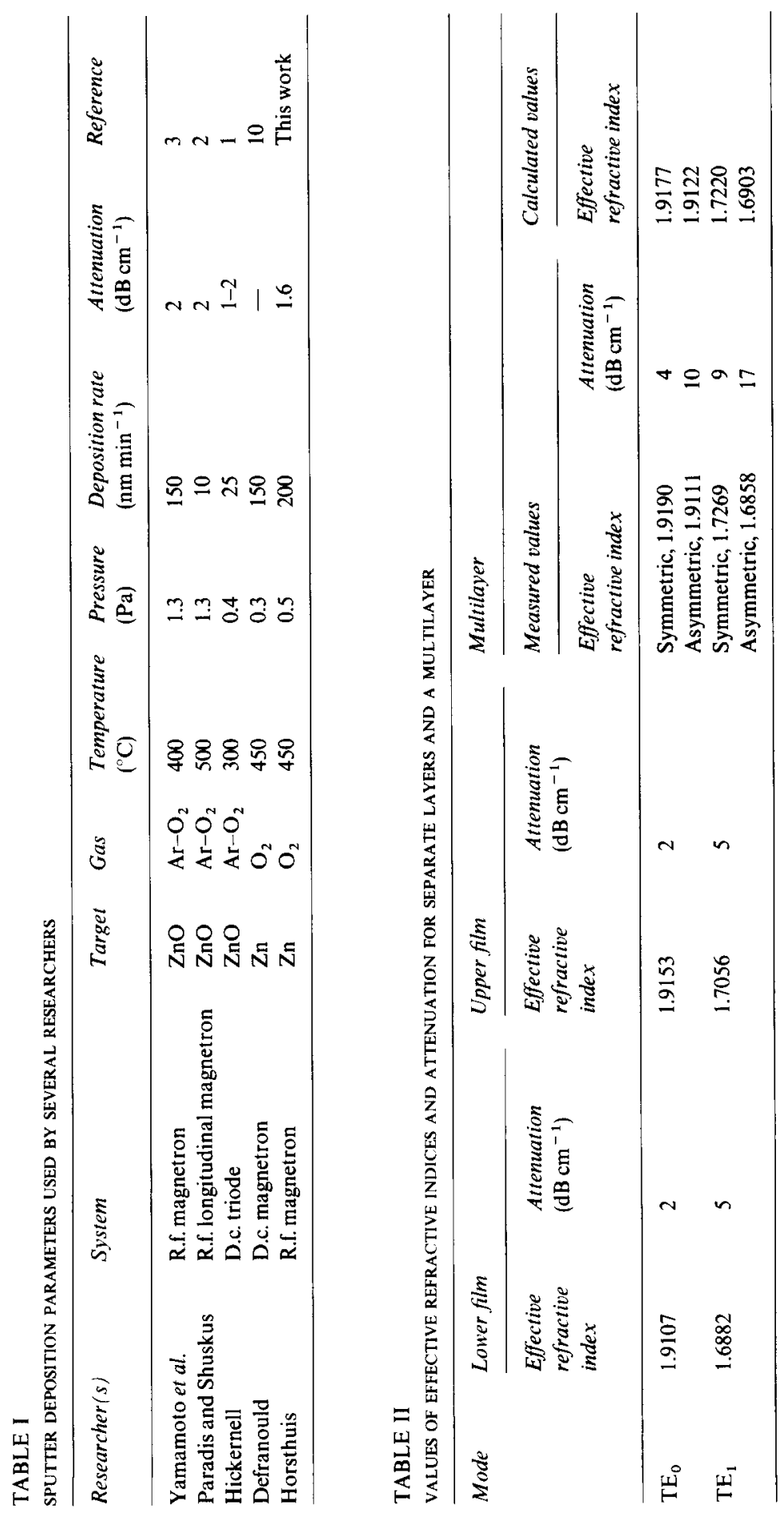


\subsection{Step coverage}

To create ridge-type waveguides we etched ridges in the $\mathrm{SiO}_{2}$ layer on the silicon wafer. It appeared that our sputter process results in a very smooth step coverage, as shown in Fig. 2. We produced ridge waveguides with a width down to $25 \mu \mathrm{m}$ without a measurable increase in optical attenuation. This width should not be taken as a lower limit. For our purposes we need slab-like waveguides, which have to remain relatively large in planar dimensions. These ridges cannot be formed by wet chemical etching since $\mathrm{ZnO}$ behaves very anisotropically in all etchants, leading to rough edges and consequently excess light scatter.

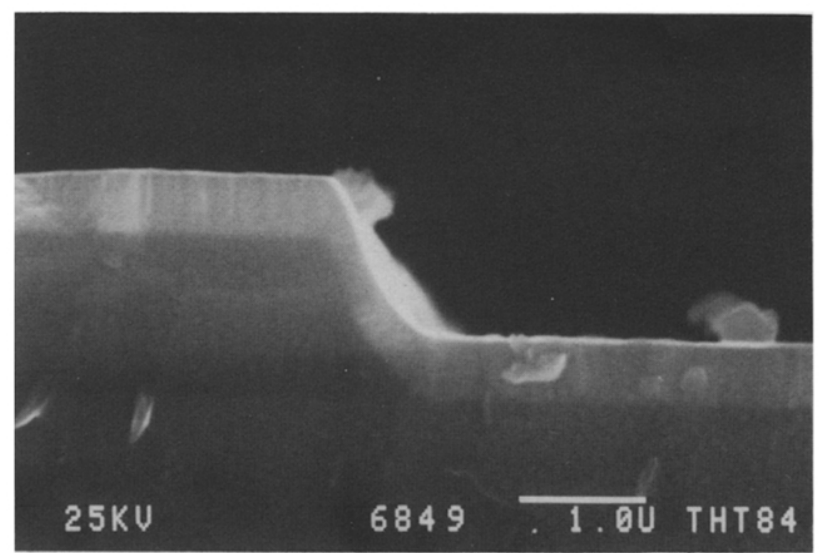

Fig. 2. Scanning electron micrograph of $\mathrm{ZnO}$ step coverage on etched $\mathrm{SiO}_{2}$ profile.

\section{MULTILAYERS}

We studied the optical behaviour of multilayered waveguides consisting of two $\mathrm{ZnO}$ layers separated by a chemically vapour-deposited $\mathrm{SiO}_{2}$ film. Structures as depicted in Fig. 3 were used; a cleaved part of a second oxidized silicon wafer is utilized as a shadow mask to sputter deposit $\mathrm{ZnO}$ only partially onto the first wafer. A computer program was written to calculate the modes for these multilayers. Propagation constants and attenuation were measured for both the separate layers and the multilayer.

The results for one multilayer are presented in Table II. From the measure-

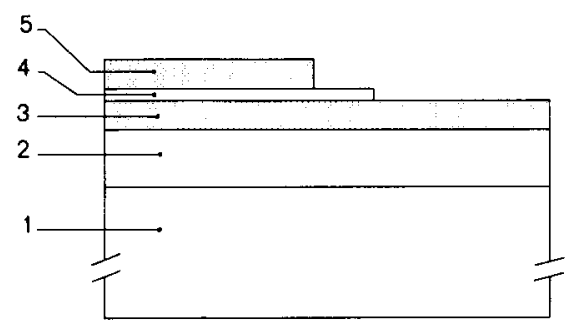

Fig. 3. Cross section of a multilayered waveguide: 1 , silicon wafer $(280 \mu \mathrm{m}) ; 2$, thermally grown $\mathrm{SiO}_{2}$ $(1 \mu \mathrm{m}) ; 3$, sputtered $\mathrm{ZnO}(0.2-0.5 \mu \mathrm{m}) ; 4$, partially chemically vapour-deposited $\mathrm{SiO}_{2}(0.2 \mu \mathrm{m}) ; 5$, partially sputtered $\mathrm{ZnO}(0.2-0.5 \mu \mathrm{m})$. 
ments of the separate layers, the refractive indices and thicknesses of these layers can be determined. These values together with the thickness and refractive index of the separating layer are fed into the computer which then calculates the mode effective indices of the multilayer itself, which are given in the last column. Results for other multilayers are quite similar.

We also calculated the spatial intensity profiles of the electric fields of the modes and plotted them as shown in Fig. 4. The intensity profiles of the symmetric and antisymmetric modes mainly depend on the thickness ratio of the two $\mathrm{ZnO}$ layers, and on the thickness of the intermediate layer. Figure 4(a) presents the results for a multilayer with equal $\mathrm{ZnO}$ layers. In Fig. 4(b) the thickness of the upper layer is decreased by $10 \%$. As can be seen, the spatial distribution of the propagated power is greatly changed. It can be easily explained from these plots why the attenuation coefficients for the symmetric and antisymmetric modes are different. In the case of the antisymmetric modes, a larger part of the energy propagates in the upper $\mathrm{ZnO}$ layer. This layer exhibits larger losses since it is sputtered onto a poor quality intermediate layer. For reference, we sputtered $\mathrm{ZnO}$ films onto chemically vapourdeposited $\mathrm{SiO}_{2}$ films which were directly deposited onto cleaned silicon wafers. The loss of the $\mathrm{TE}_{\mathrm{o}}$ mode was about $7 \mathrm{~dB} \mathrm{~cm}^{-1}$, compared with $2 \mathrm{~dB} \mathrm{~cm}^{-1}$ which is typical for films on steam-oxidized wafers.

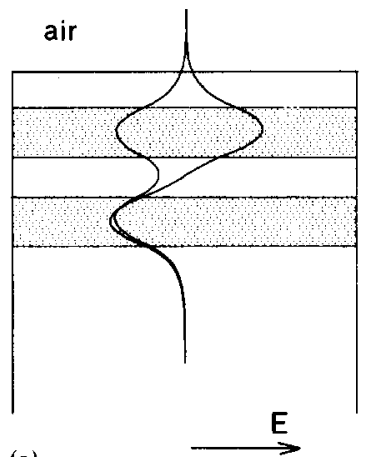

(a)

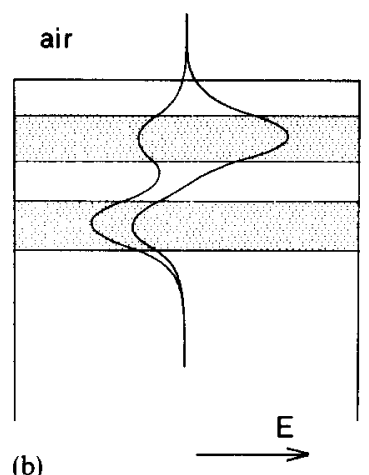

(b)

Fig. 4. Electric field strength of guided TE modes in multilayers (shaded areas, $\mathrm{ZnO}$; white areas, $\mathrm{SiO}_{2}$ ): (a) symmetric multilayer (thicknesses: $\mathrm{ZnO}$ layers, $0.25 \mu \mathrm{m}$; separating layer, $0.2 \mu \mathrm{m}$ ); (b) asymmetric multilayer (thicknesses: upper $\mathrm{ZnO}, 0.23 \mu \mathrm{m}$; lower $\mathrm{ZnO}, 0.25 \mu \mathrm{m}$; separating layer, $0.2 \mu \mathrm{m}$ ).

For the asymmetric case the energy of both modes is more clearly split over the two layers. Consequently the difference in attenuation of both modes is also increased. These sandwiched structures can be used for mode coupling purposes, such as switching and modulating or for sensor applications. We developed a guided TE-to-TE coupler for sensor applications, the details of which are presented elsewhere ${ }^{13}$. Figure 5 shows a cross section of the mode coupler. This device could be regarded as a modified directional coupler, where the two channel waveguides are replaced by two slabs. The advantage of this configuration is the reduction in the accuracy required for the fabrication.

A periodic electrode is deposited on top of the multilayer. The reverse side of the wafer is metallized to form the ground electrode. The wafer itself may be regarded as 


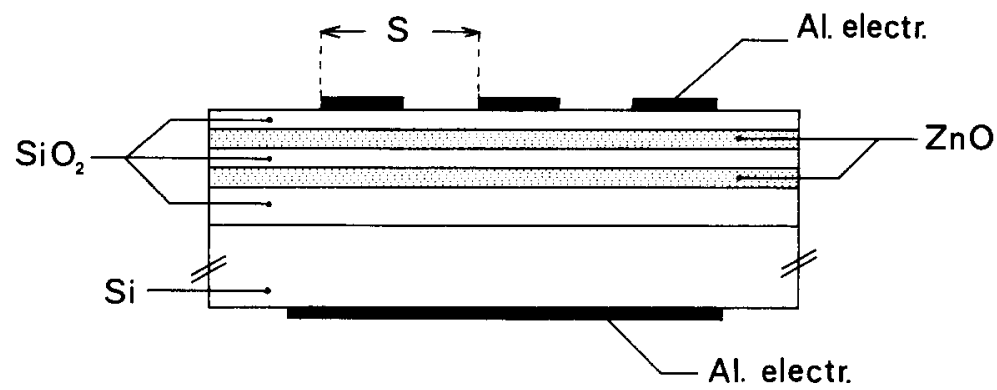

Fig. 5. Cross section of a guided TE-to-TE mode coupler.

a ground electrode since it has a very low resistivity $(3 \Omega \mathrm{cm})$. The spacing between the two opposite electrodes is therefore very small, usually being about $1.8 \mu \mathrm{m}$, which results in rather homogeneous electric fields in the multilayer. The antisymmetric mode is coupled to the waveguide by means of a rutile prism. An applied voltage on the electrodes couples energy to the symmetric mode. Using a second prism, light is again coupled out and both modes can be measured separately. In order to couple, the spatial period $A$ must match the effective index difference between the two modes according to

$$
\Lambda=\frac{\lambda_{0}}{\Delta N_{\text {eff }}}
$$

By rotating the wafer with respect to the prisms this period can be varied as follows:

$$
\Lambda=\frac{s}{\sin \alpha}
$$

where $\alpha$ is the angle between the light beam and the electrodes and $s$ is the deposited electrode periodicity.

Figure 6 shows the response of the mode coupler. The interaction length $L$ was $2 \mathrm{~mm}$ or 124 periods. The sensitivity is dependent on the interaction length. The electrode pattern can be optimized for a maximum electric field modulation depth,

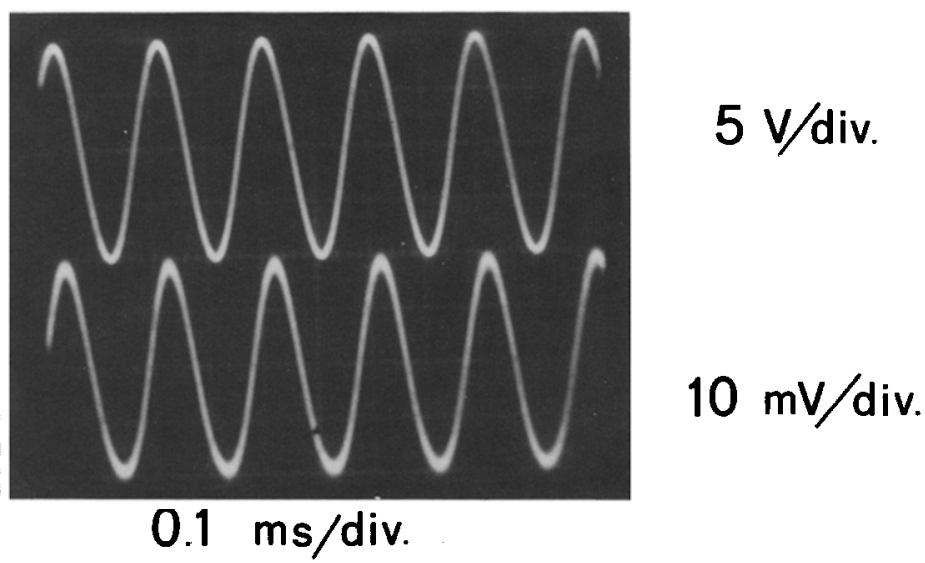

Fig. 6. Oscilloscope picture of mode coupler response: upper trace, driving voltage; lower trace, response of the symmetric mode (antisymmetric mode was launched). 
and also to improve the sensitivity. We expect to improve the coupler to a $100 \%$ modulation for about $10 \mathrm{~V}$.

\section{CONCLUSIONS}

We found that the optical quality of the sputtered $\mathrm{ZnO}$ films increases approximately linearly with increasing deposition rate (up to $220 \mathrm{~nm} \mathrm{~min}^{-1}$ ). Results are very reproducible with respect to refractive indices and optical attenuation.

The sputter process gives excellent step coverages on etched $\mathrm{SiO}_{2}$ profiles, making the production of low loss waveguiding channels feasible.

We developed a guided TE-to-TE mode coupler based on a multilayered waveguide. Good results were obtained with a first prototype which had a very short interaction length $(2 \mathrm{~mm})$. Increasing this length and optimizing the electrode pattern is expected to improve the sensitivity to a full-modulation voltage of $10 \mathrm{~V}$.

\section{ACKNOWLEDGMENT}

These investigations were supported (in part) by The Netherlands Technology Foundation (STW).

\section{REFERENCES}

1 F. S. Hickernell, Low loss zinc oxide optical waveguides on amorphous substrates, Proc. 5th Topical Meet. Integrated and Guided Wave Optics, Incline Village, January 28-30, 1980, IEEE, New York, 1980, p. WB6-1.

2 E. L. Paradis and A. J. Shuskus, R.f.-sputtered epitaxial ZnO films on sapphire for integrated optics, Thin Solid Films, 38 (1976) 131-141.

3 T. Yamamoto, T. Shiosaki and A. Kawabata, Characterization of $\mathrm{ZnO}$ piezoelectric films prepared by r.f. planar-magnetron sputtering, J. Appl. Phys., SI (1980) 3113-3120.

4 M. Izutsu, E. Enokihara and T. Sueta, Optical waveguide micro-displacement sensor, Electron. Lett., 18 (1982) 867-868.

5 L. M. Johnson, F. J. Leonberger and G. W. Pratt, Jr., Integrated optical temperature sensor, Appl. Phys. Lett., 41 (1982) 134-136.

6 C. H. Bulmer, R. P. Moeller and W. K. Burns, Linear Mach-Zehnder interferometers in $\mathrm{LiNbO}_{3}$ for electromagnetic field sensing, Proc. Eur. Conf. on Integrated Optics, Florence, October 17-18, 1983, Institution of Electrical Engineers, London, pp. 140-143.

7 O. Parriaux and F. Cochet, Characterization method of birefringent films by guided optical waves, Opt. Lett., 9 (1984) 484-486.

8 M. D. Ambersley and C. W. Pitt, Piezoelectric $\mathrm{ZnO}$ transducers produced by r.f. magnetron sputtering, Thin Solid Films, 80 (1980) 183-195.

9 B. T. Khuri-Yakub, J. G. Smits and T. Barbee, Reactive sputtering of ZnO using a planar magnetron, Proc. Ultrasonics Symp., Boston, 1980, Vol. 2, IEEE, New York, 1980, pp. 801-804.

10 Ph. Defranould, High deposition rate sputtered $\mathrm{ZnO}$ thin films for BAW and SAW applications, Proc. 1981 Ultrasonics Symp., IEEE, New York, 1981, pp. 483-488.

11 S. Maniv, W. D. Westwood and E. Colombini, Pressure and angle of incidence effects in reactive planar magnetron sputtered ZnO layers, J. Vac. Sci. Technol., 20 (1982) 162-170.

12 S. Maniv and A. Zangvilli, Controlled texture of reactively r.f. sputtered $\mathrm{ZnO}$ thin films, J. Appl. Phys., 49 (1978) 2787-2792.

13 W. H. G. Horsthuis and R. Pannekoek, Electrooptic modulators in multilayered zinc oxide waveguides, Proc. 3rd Eur. Conf. on Integrated Optics, Berlin, May 6-8, in Springer Series in Optical Sciences, Vol. 48, Springer, Berlin, 1985, pp. 152-157. 